\section{NOTÍCIAS UNIVERSITÁRIAS}

\section{- IDEAL UNIVERSITÁRIO}

Dia $10^{\circ}$ de Julho de 1948 , por ensejo do lançamento da pedra funda. mental das novas obras da Universidade do Rio Grande do Sul e quando, simultâneamente, se fundava a Associação dos Professôres Universitários, - Prof. Armando Câmara, ao tempo Reitor Magnífico da Universidade, proferiu a seguinte oração:

"Uma Universidade, dissemos alhures, não consiste tão só numa fonte de sabedoria e de ciência, numa energia espiritual luminosa e irradiante; é, ainda, uma organização de convívio; situa-se num espaço social; uma administração, uma realidade que se insere no mundo das cousas, dos objetos materiais, dos valores úteis e econômicos. Essa mensagem do espírito de que ela é portadora, essa comunicacão que deve fazer de uma sabedoria, a Universidade realiza-a através de homens e pela utilização de objetos.

O ideal universitário, para que se possa concretizar e exercer sua ação transfiguradora, exige a oferenda de vidas humanas votadas à contemplação desinteressada da verđade, à pesquisa, à exploração do mistério do sêr, enfim ao saker e à técnica. Exige, também, quadros materiais de realização, laboratórios, gabinetes, um espaço construído, um cenário próprio.

Amparar o portador da cultura, o professor, criar meios materiais para que atui com eficiência, são condições que, não atendidas, transfor mariam uma Universidade numa caricatura de algo sagrado para a inteligência. Um govêrno universitário que descurasse o tratamento dessas exigências, estaria na iminência de confundir a comunicação da ciência com a difusão do charlatanismo.

Senhores - Inteligência servida por órgãos, na criticada definição de De Bonald, animal racional, o homem, em seu esfôrco criador da cultura, está condicionado a um duplo espaço: psicológico-social e físico.

O surto das chamadas escolas da sabedoria clássica, greco-romana, traduz êste duplo condicionamento na constituição do saber humano.

A Academia de Platão e o Liceu de Aristoteles não expressaram, apenas, a existência de uma equipe de pensadores, de um grupo de discípulos em torno de um mestre; foram, ainda, originariamente, casas, edifícios escolares, vulgares construções, massas arquitetônicas, localizadas em determinadas regioes de Atenas, e que integravam tudo que, "in illo tempore", era considerado necessário e conveniente ao processamento da cultura.

A realidade inextensa do espírito insere-se, emerge na realidade extensa das cousas. As intuiçoes do gênio que descobre, as criações do talento que inventa, realizam-se, em verdade, meta-espacialmente.
Mas, as descobertas e as invençôes do espírito só vãd constituir bens culturais quando se objetivam e se fazem transferíveis, comunicáveis, encarnando-se em cousas, concretizando-se, fazendo-se objetos de ensino, de demonstração, de crítica e de aprendizagem.

E essa objetivação das produções do pensamento, exige espaço adequado à sua universal aquisição pelas inteligências.

Como a Técnica exige o espaço da fábrica, como a Mística exige o espaço do templo, como o amor exige o espaço do lar, assim o saber exige o espaço da Escola - seja ela Liceu ou Academia, seja Anfiteatro ou Laboratório, espaço necessário para a demonstração de um teorema ou para a observação do comportamento das afinidades atômicas e das reações dos microrganismos.

Mas, como a Técnica, como a Mística e como o Amor, o Saber exige, igualmente, o fenomeno do convivio, pressupôe o espaço social, um contexto de energias inter-psicológicas, implica a existência da escola, no sentido sociológico da palàvra.

Senhores - Nesta sessão de Assembléia Universitária, convocada para o lançamento de duas fundações - a de um edifício $\epsilon$ a de uma associação, atendemos a essa dupla necessidade de tôda organização cultural: a de espaço físico e a de espaço psicologico-social.

Era deprimente para nós sermos passivas testemunhas dêsse espetáculo de uma Universidade oficial com duas Faculdades - a de Economia e a de Filosofia, sem sede propria, com duas tradicionais escolas a de Engenharia e a de Agronomia, situadas em condiçôes materiais deploraveis, em edificios inadequados as exigencias de sua crescente população escolar e à progressiva complexidade de seus cursos; com Institutos carentes do necessário aparelhamento tes povoados de equipamento fóssil, revelando incoercível vocação para se constituírem em museus exemplares..

Permanecermos impassíveis face a essa indigência ou consolarmonos com a visão de uma futura Cidade Universitária, seria trair elementar dever funcional. A fidelidade a êsse imperativo compeliu-nos a agir oportuna e, talvez, importunamente, para que se corrigisse essa comprometedora anomalia pedagógica. Nosso clamor e nossa ação não foram infecundos; a palavra e o gesto reivindicadores suscitaram enfim, como vêdes, a satisfação da necessidade vital. O lançamento desta pedra fundamental revela-nos que, em verdade, pronunciamos palavras construtivas.

Não é, ainda, a fundação de uma Cidade, talvez mesmo não seja nem a de uma Vila Universitária, a que hoje iniciamos; de qualquer modo, certo é que, neste ato, damos um definitivo adeus, e sem nenhuma melancolia, à ameaçadora visão de uma maloca universitária...

Lançando os fundamentos desta construção monumentalal, atendemos, apenas, voltados para o presente e para o concreto, inadiaveis exigencias da instituição sob nosso govêrno. Com êste gesto não renunciamos, de modo algum, às providências relativas à construção da futura Cidade Universitária, obra que, pelo seu vulto, pelas dificuldades múltiplas que encerra sua realizaçao, exigirá, para ser concluida, um decurso de tempo que, sem grave desprestígio cultural de nossa Universidade, não poríamos aguardar.

Senhores - Quero, neste momento, cumprir um dever de justiça. A satisfação que nesta hora começamos a dar a vital necessidade de espaço construído, de que padecia nossa Universidade, muito deve ao Senhor Governador do Estado. Sua Excelencia revelou, no tratamento dêsse problema básico de nossa instituição, um alto espirito público 
uma nobre compreensão. Quero expressar-lhe, por esta sua atitude, o apreço e a gratidáo da Universidade do Rio Grande do Sul.

Senhores - As condições em que surgiram, na América, as Universidades, não coincidem com as que determinaram sua gênese, na Europa. La, ha mais de 7 séculos, no interior da uma civilização hígida, possuidora de uma vigorosa unidade espiritual, o sistema universitário caracterizava-se pela posse de uma enérgica visão unitária do sêr, dominando todo o panorama de uma multiplicidade de formas especializadas do saber.

Sua constituição resultou de uma extensão feliz do direito corporativo à esfera de ação dos homens votados à cultura. Foi um elấ vibrante de solidariedade de classe, foram os vinculos criados por uma mesma vocação, por um comum ideal, que geraram as primeiras Universidades Dois traços a caracterizavam: a unidade do saber e a solidariedade, o convívio íntimo e a íntima colaboração dos portadores da cultura que as integravam.

Bem diversas foram as condições em que surgiram, entre nós, as universidades. Preliminarmente, vivemos no interior de uma civilizaçáo cuja unidade espiritual fol fraturada. Acresce que a cultura supe rior, entre nós, processou-se através de escolas e faculdades isoladas, que proporcionavam o saber rigidamente profissional.

Nossas universidades constituíram-se pela reunião dessas escolas, sob o ínfluxo de iniciativas políticas do Estado. Nelas existe menos um sistema, que um conglomerado cultural. Constituem, ainda, simples unidades administrativas. Nelas, não se traduz a existência de um espírito universitário, que pressupõe convívio demorado, comunicação de ideias de experiências, de pesquisas em tôrno de problemas comuns.

Carecemos, lamentàvelmente, de um espaço psicológico-social, indispensável à constituição de uma cultura integral. Para merecer o nom que traz, nossa Universidade deverá constituíl-lo. E ela poderá fazê-lo precipuamente, organizando o convívio de seus mestres e de seus alunos, proporcionando-lhes, através de vivências, tìpicamente universitárias, a consciência do ideal comum.

Senhores - Foi para ofertar à nossa incipiente Universidade essa situação, necessária à sua existência normal e específica, que, hoje, lança mos as bases da Associação dos Professôres Universitários.

Complexo, vital é o seu programa de ação. Realizado, êle transfor mará a vida Universitária, nela gerando uma autêntica e vigorosa unidade cultural.

Senhores professôres e senhores acadêmicos - Testemunhais, nesta Assembléia, duas iniciativas que nada têm de decorativas e protocolares elas expressam gestos que queremos sejam criadores de realidades, ato que esperamos sejam constitutivos da Universidade do Rio Grande do Sul. Apelamos para vossa colaboração e cremos que vos transformareis de testemunhas, em fecundos operários dêsse nobre labor que, nesta hora, se inicia. Disse".

\section{A CONFERENCIA DE DOM GIUSEPE RICCIOTTI}

Realizou-se, no salão nobre da Faculdade de Direito da Univer. sidade do Rio Grande do Sul, uma conferência do Revdmo. Dom Giu sepe Ricciotti, professor da Universidade de Roma, e autoridade mun dialmente reconhecida em assuntos orientais, mormente no que diz respeito à Palestina. A conferência de Dom Ricciotti versou sôbre o Problema da Palestina, tendo o conferencista abordado magistralmente a questão, focalizando-a sob todos os seus múltiplos e diversos prismas, afirmando que sòmente a internacionalização de Jerusalém poderá pôr têrmo às divergências e atritos. Numeroso público compareceu ao salão nobre da Faculdade de Direito, a fim de ouvir o ilustre conferencista, destacando-se grande número de membros do corpo docente da Universidade do Rio Grande do Sul, e outras pessoas gradas.

Saudando a Dom Ricciotti, falou o prof. José Salgado Martins, diretor da Faculdade de Direito da Universidade do Rio Grande do Sul, proferindo a oração que segue:

"Exmo. Sr. Arcebispo Metropolitano. Eminente Sr. Dom José Ricciotti. Srs. Professôres. Senhoras e Senhores.

Poucas vêzes, à Faculdade de Direito tem sido conferida honra tão insigne quanto a que desfruta, nesta noite, recepcionando o eminente senhor Dom José Ricciotti. A presença de Dom José Ricciotti e a palavra do brilhante historiador e do profundo exegeta de milenárias civilizações, que vamos ouvir e recolher como as fulgurações do seu extraordinário espírito, revestem-se de inofuscável significaçáo para nós, brasileiros e rio-grandenses, tão ìntimamente ligados, pela sensibilidade do espírito, pelos pendores do mesmo temperamento latino, pela formação cristã de nossa vida individual e coletiva, às perenes correntes espirituais a que se abebera a pátria italiana, herdeira direta do le. gado imortal da latinidade. Cresce ainda de vulto a sua presença nesta Faculdade, porque o conferencista desta noite é uma das altas expressóes da cultura universitária da sua pátria, como professor da Régia Universidade de Roma. Pesquisador profundo dos enigmas de velhas civilizações, vem reconstruindo as origens e as características daqueles povos de pastôres e profetas que, nos reinos de Israel e de Judá, povoaram as paragens bíblicas do Oriente.

Dom José Ricciotti, na sua notável "História de Israel, das origen a exílio", não fêz obra de imaginação ou de simples intuição psicológica, mas realizou pesquisa histórica, de cunho científico, amplamente documentada, segura nos juízos e nas conclusões. Mas, por outro lado, não se confina a sua obra à restauração fria e impassível do passado histórico fo ao contrário, um resumo cálido do espírito que animou os acontecimentos históricos, que dinamizou os lances mais significativos, que marcou as grandes linhas e os profundos motivos do seu apogeu ou do seu ocaso. A história não é para Dom José Ricciotti a simples reproducão dos fatos na sucessão dos episódios no tempo. A história é a vida, é a síntese do processo sociológico, desvendado nos seus segredos pela visão percuciente do filósofo. 0 juízo do historiador é mais amplo e mais profundo do que a simples evocação do historiógrafo 
Enquanto êste descreve, aquêle interpreta. Um registra os acontecimentos, outro busca o seu sentido íntimo e, ligando-os ao panorama universal da vida, determina as leís gerais da sua evolução, destaca os fatôres que the condicionaram a gênese e fixa a posição do fato histórico, como viva intercessão dos mais variados elementos, presentes na fenomenologia social.

$\mathrm{Na}$ "História de Israel", o seu ilustre autor mostra que o profetismo constitui o centro de gravitação de tôda a vida do povo do Velho Testamento.

"Assim como num oásis, rodeado pelo árido deserto, o segrêdo de sua vegetação luxuriante reside no manancial inexaurivel que irriga as palmeiras e as outras plantas, assim também foi o profetismo na história de Israel a "fonte de água viva", por meio da qual Yahvé manteve a sua nação, sob o florescimento sempre renovado" (História de Israel, pág. $344-45$ )

"A atitude das massas frente aos profetas foi a atitude ordinàriamente assumida pelos pigmeus morais frente aos gigantes: uma postura ilógica, mutável, variando entre a veneração e o repúdio, entre a fé e a incompreensão que no momento de bestial exasperação lapidava o gigante para logo depois, com as mesmas pedras salpicadas de sangue, erigir-lhe um monumento. Mas, mesmo no meio de suas violências contra os profetas, o povo pressentia confusamente a enorme importância daquela missão na vida nacional.

"Muitas vêzes, os profetas foram comparados às sentinelas colocadas em altas tôrres para sinalar a proximidade do inimigo, às escoltas que vigiam a segurança do acampamento, às guardas noturnas que espiam na insidiosa escuridade; por isso, o povo, ainda quando enfastiado com o alarma de semelhante escolta, sentia a superioridade de sua missão.

"Israel se havia habituado, com efeito, a êsses gritos de alarma e a ver surgir um profeta, especialmente, nos tempos mais críticos. Quando periòdicamente, revolvia-se sôbre o povo a tormenta, condensada, durante anos, pelos seus próprios delitos, sabia-se que Yahvé, nesse momento, juntamente com a praga, enviaria a medicina e que, ao mesmo tempo, com a catástrofe chegaria o ditador espiritual que reconstruiria o destruído." (ob. cit., pág. 360-61, n. 430).

Depois, as adversidades acumularam-se sôbre o povo e, nos últimos tempos, não se levantava mais sôbre as cabeças desalentadas a voz pacificadora ou rugidora do profeta.

"O astro do profetismo estava no ocaso. Havia cumprido a sua missão, dissipando as trevas da noite. Avizinhava-se a claridade matinal do grande dia." (ob. cit. pág. 361).
E o aparecimento d'Aquele que seria a eclosão de uma manhã radiosa na face do mundo, dando-lhe a unidade de uma doutrina, doutrina feita de caridade e de amor, em que já não caberiam os delírios. do profetismo e as explosões do ódio ou a total submissão aos valores. transitórios da terra, a história de Cristo, que é a história das origens divinas do cristianismo, encontrou ainda em Dom José Ricciotti o extraordinário exegeta que confundiu, com a sua crítica certeira, a falácia do racionalismo pseudo-científico que se confessou incapaz de compreender a sobrenaturalidade de Cristo, sob a condição natural de sua. humanidade.

Senhor Dom José Ricciotti: A Faculdade de Direito da Universidade do Rio Grande do Sul, recepcionando-vos nesta noite e tributandovos as homenagens do seu respeito e da sua admiração, está recolhendo, para os anais da vida acadêmica, insigne honra que a desvanece, e, ao mesmo tempo, está manifestando exemplar fidelidade aos grandes princípios que definem a sua vocação universitária, pois esta sòmente pode afirmar-se no quadro da espiritualidade cristã fora do qual se desnatura a essência do homem. Bem-vindo seja o insigne historiador cristão a esta modesta casa onde se ensina e se cultua o Direito, princípio imanente de Deus na consciência dos povos e dos homens." 